\title{
PENGEMBANGAN TUGAS-TUGAS BIOLOGI DALAM PENINGKATKAN MINAT BELAJAR SISWA
}

\author{
Salim ula, Endang Gunaisah’ Azhari Ridho’
}

Program studi pendidikan biologi STKIP Muhammadiyah Sorong

\begin{abstract}
ABSTRAK
Untuk Mengetahui Bagaimana Minat mengerjakan tugas-tugas siswa di SMP Negeri 13 Raja Ampat Kampung Jefman.Untuk Mengetahui Faktor-faktor apa saja yang mempengaruhi minat siswa dalam mengerjakan tugas Biologi.Untuk Mengetahui Bagaimanakah SMP Negeri 13 Raja Ampat Kampung Jefman. Sampel terdiri dari siswa kelas VIII di SMP Negeri 13 Raja Ampat Kampung Jefman. Peneltian berupa Penelitian Tindakan Kelas (PTK) direncanakan pada tanggal 18 juli sampai dengan tanggal 30 agustus 2016. Prosedur atau langkah-langkah penelitian yang dilakukan terbagi dalam bentuk siklus dimana setiap siklus terdiri atas empat kegiatan pokok adalah kegiatan perencanaan tindakan pelaksanaan, observasi dan refleksi. Empat kegiatan ini berlangsung secara singkat yang urutannya dapat mengalami modifikasi. Hasil pengambilan data dengan mengunakan angket konsuiner di siklus pertama atau siklus ke satu ada enam belas siswa yang hadir. Hasil Observasi pada siklus ke satu ini di lakukan pada saat pembelajaran berlangsung. Siswa di bagi menjadi empat kelompok. Disiklus ke satu ini penulis melakukan belajar mengajar terlebih dahulu. Buku yang di gunakan oleh penulis yaitu Belajar IPA Membuka Cakrawala Alam Sekitar untuk kelas VIII Sekolah Menengah Pertama/Madrasah Tsanawiyah. Saeful karim, dkk Materi yang di berikan kepada siswa BAB I tentang Pertumbuhan Dan Perkembangan pada makhluk hidup. penulis memberikan tugas kepada siswa tugas yang di berikan kepada siswa yaitu tentang tahapan perkembangan manusia. Minat adalah kecendrungan subjek untuk merasa tertarik pada mata pelajaran atau pokok bahasan tertentu dan merasa senang mempelajari materi itu. Besar kecilnya minat akan mempengaruhi keberhasilan bagi setiap kreativitas manusia. Faktor -faktor yang mempengaruhi siswa kelas VIII adalah siswa yang masih menunjukan tidak keaktifan dalam proses pembelajaran, seperti melamun, mengantuk, tidak memperhatikan pembelajaran, tidak bertanya kepada guru tentang materi yang belum jelas, tidak menjawab pertanyaan dari guru, tidak mengerjakan tugas, dan sibuk aktivitas masing-masing misalnya bicara sendiri.
\end{abstract}

Kata kunci : tugas-tugas biologi, minat belajar, jefman.

\begin{abstract}
To Learn How Interests tasks students of SMP Negeri 13 Kampung Raja Ampat Jefman.Untuk Knowing the factors that influence students' interest in doing Biologi.Untuk Knowing How SMPN 13 Jefman Kampung Raja Ampat. The sample consisted of eighth grade students at SMP Negeri 13 Jefman Kampung Raja Ampat. Peneltian form of classroom action research (PTK) is planned on the 18th of July until the 30th August 2016. The procedures or measures divided the research conducted in the form of cycles where each cycle consists of four main activities are the activities of the action plan implementation, observation and reflection. Four of these activities take place in short order can be modified. The results of data collection using the questionnaire konsuiner in the first cycle or cycles to the sixteen students who attended. Observations on this one in the cycle to do when learning takes place. Students were divided into four groups. Cycled to one writer do the learning first. A book that is in use by the author of Learning Science Horizons Opens Nature Around for class VIII School SMP / MTs. Saeful karim, et al material that is provided to students Chapter I on Growth and Development in living beings. author gives assignments to the students the task that is given to students is about the stages of human development. Interest in the subject is a tendency to feel attracted to subjects or subjectspecific and were delighted to learn the material. The size of interest will affect the success of every human creativity. The factors that influence the eighth grade students are students who still showed no activity in the learning process, such as the dreamy, drowsy, not paying attention to learning, not to ask the teacher about the matter is not yet clear, did not answer questions from the teacher, do not do the work, and busy activity each instance talking to himself.
\end{abstract}

Keywords: biology tasks, interest, Jefman.

\section{Pendahuluan}

Dalam meningkatkan pembangunan di Indonesia dibutuhkan Sumber Daya Manusia (SDM) yang berkualitas, agar pembangunan berjalan dengan baik dan lancar sesuai dengan salah satu tujuan negara yaitu memajukan kesejahteraan umum dan mencerdaskan kehidupan bangsa, maka salah satu jalan yang harus ditempuh yaitu melalui bidang pendidikan.
Pendidikan di Indonesia merupakan suatu upaya untuk bangsa Indoensia menjadikan negara Indonesia menjadi lebih maju dan berkembang. Sedangkan dunia pendidikan di Indoensia masih sangat kurang serta jauh tertinggal dari negara-negara berkembang lainnya, indeks pembangunan manusia (IPM) Indonesia di tahun 2008 menempati urutan ke109 dengan indeks 0,762 jauh dari negara-negara tetangga seperti Malaisya dan India, perlu diketahui 
bahwa semakin tingginya IPM pada suatu negara maka kesejahtraan negara tersebut semakin tinggi pula.

Upaya perbaikan dan peningkatan kualitas pendidikan di Indonesia terus menerus dilakukan oleh pemerintah, baik secara konfensional maupun inovatif mengingat pendidikan adalah suatu kekuatan yang dinamis dalam kehidupan setiap indifidu yang mempengaruhi perkembangan fisik, daya jiwa (akal, rasa, dan kehendak), sosial dan moralitas (Sumitro, dkk 2003: 16). Kurikulum yang saat ini diberlakukan semaksimal mungkin mengakomodasi segala bentuk perkembangan dan kemajuan ilmu pengetahuan dan teknologi (IPTEK), sehingga siswa dituntut untuk memiliki keterampilan dan kemampuan yang sesuai dengan perkembangan dan kemajuan IPTEK. Kondisi pembelajaran yang tertinggal merupakan suatu kemunduran dunia pendidikan dalam melahirkan peserta didik yang cerdas dan berkecakapan menjawab tuntutan kurikulum.

Kenyataan dilapangan menunjukan masih banyak permasalahan yang terjadi didunia pendidikan Indonesia seperti dalam pembelajaran IPA Biologi di sekolah. Permasalahan yang terjadi adalah rendahnya minat belajar siswa. Ada tiga faktor utama yang mempengaruhi hasil belajar yaitu kemampuan kognitif, motivasi berprestasi dan kualitas pembelajaran (Bloom 1982). Pengembangan minat belajar siswa dapat didukung oleh beberapa hal salab. satunya yaitu peningkatan tugas-tugas belajar. Sejauh mana penelitian yang dilakukan tentu mempunyai sasaran yang hendak dicapai atau menjadi tujuan penelitian. Adapun yang menjadi tujuan penelitian ini adalah :

1. Untuk Mengetahui Bagaimana Minat mengerjakan tugas-tugas siswa di SMP Negeri 13 Raja Ampat Kampung Jefman.

2. Untuk Mengetahui Faktor-faktor apa saja yang mempengaruhi minat siswa dalam mengerjakan tugas Biologi.

Untuk Mengetahui Bagaimanakah pengembangan tugas-tugas guna meningkatkan minat belajar siswa.

\section{METODE PENELITIAN}

Peneltian berupa Penelitian Tindakan Kelas (PTK) direncanakan pada awal bulan mei 2016 dan berakhir pada awal bulan juni 2016, Prosedur atau langkah-langkah penelitian yang dilakukan terbagi dalam bentuk siklus kegiatan mengacu pada model yang diadopsi dari Hopkins (1993:48), dimana setiap siklus terdiri atas empat kegiatan pokok adalah kegiatan perencanaan tindakan pelaksanaan, observasi dan refleksi. Empat kegiatan ini berlangsung secara singkat yang urutannya dapat mengalami modifikasi. Desain penelitian tindakan kelas mengikuti desain model lewiz yang di tafsirkan oleh kemmis (Rochitia Wiraatmadja).

\section{Refleksi awal}

Pada tahap ini dilakukan indentifikasi kesulitan siswa dalam memahami pelajaran Biologi

\section{Perencanaan tindakan}

Masalah yang ditemukan akan diatasi dengan melakukan langkah-langkah perencanaan tindakan untuk menyusun instrument penelitian berupa : lembar observasi, soal test, angket minat siswa, dan lembar kegiatan siswa (LKS).

3. Pelaksanaan Tindakan

Pada tahap ini dilakukan tindakan berupa pelaksanaan program pembelajaran, pengambilan atau pengumpulan data hasil angket, lembar observasi dan hasil test.

4. Observasi Refleksi dan Evaluasi

Tahapan ini dilakukan pengumpulan data-data dan menganalisis untuk kemudian data diambil kesimpulan dari penelitian.

Untuk dapat memudahkan penelitian ini dan agar penelitian memiliki arah yang jelas dalam menginterpretasikan fakta dan data ke dalam penulisan skripsi, maka terlebih dahulu dirumuskan Fokus Penelitian. Berdasarkan uraian latar belakang masalah diatas maka fokus penelitian dalam penelitian ini adalah :

1. Bagaimana Minat mengerjakan tugas-tugas siswa di SMP Negeri 13 Raja Ampat Kampong Jefman.

2. Faktor-faktor apa saja yang mempengaruhi minat siswa untuk mengerjakan tugas Biologi di SMP Negeri 13 Raja Ampat Kampung Jefman.

Bagaimanakah pengembangan tugas-tugas untuk meningkatak minan belajar siswa di SMP Negeri Kampung Jefman.

4. Macam data, Instrumen Penelitian dan Teknik Pengumpulan Data

1. Macam Data

Data yang diambil dalam penelitian ini meliputi : minat siswa terhadap mata pelajaran Biologi, kesiapan belajar siswa saat mengerjakan tugas-tugas, dan pemahaman konsep siswa terhadap materi.

2. Instrumen Penelitian

a. Angket (Kuesioner)

Kuensioner adalah pertanyaan-pertanyaa yang disusun secara tertulis dalam sebuah daftar isian.peneliti mengunakan pertanyaan terstruktur atau tertutup, dengan membuat secara tepat dan terinci. Pertanyaan/pernyataan tentang minat siswa terhadap tugas-tugas biologi . sendangkan jumlah kuesioner yang diajukan kepada siswa berjumlah 10 butir pertanyaan.

3. Lembar Observasi

Aktivitas siswa selama proses pembelajaran berlangsung diamati dengan menggunakan lebar observasi. Pengamatan difokuskan pada saat berlangsungnya pelajaran.

4. Teknik Pengumpulan Data

Teknik pengumpulan data tentang pengembangan tugas-tugas Biologi dalam meningkatkan minat siswa didapat melalui pengisian angket oleh siswa. Data aktifitas siswa diperoleh dengan pengamatan langsung menggunakan lembar observasi yang telah dipersiapkan. Data tentang 
pemahaman dilihat dari hasil dan antosias dalam mengerjakan tugas. Indikator Keberhasilan Bersuber pada tingkat kemauan siswa dalam mengerjakan tugas-tugas Biologi diharapkan adanya peningkatan kemauan siswa dalam mengerjakan tugas-tugas yang diberikan. Minimal 75\% dari jumlah siswa memiliki kemauan dalam mengerjakan tugas-tugas yang diberikan.

Hasil angket minat siswa terhadap kemauan mengerjakan tugas

Hasil yang diperoleh dari pengisian angket tersebut dianalisis dengan menjumlahkan siswa yang mengerjakan tugas, sedangkan rentang skor dari masing-masing alternative jawaban untuk anket minat siswa adalah sebagai berikut :

Sangat setuju

Setuju

Ragu-ragu

Tidak setuju

Sangat tidak setuju

Angket kuensioner minat siswa yang terdiri dari 10 butir pernyataan.

1. Data Hasil Observasi

Penilaian dilakukan setiap ada aspek yang diamati muncul. Terdapat lima alternative penilaian yang bisa didapat adalah :

$\begin{array}{lll}\text { Sangat Baik } & (\mathrm{SB}) & =5 \\ \text { Baik } & \text { (B) } & =4 \\ \text { Cukup } & \text { (C) } & =3 \\ \text { Buruk } & \text { (BR) } & =2 \\ \text { Sangat Buruk } & \text { (SB) } & =1\end{array}$

\section{PEMBAHASAN}

Pembahasan hasil penelitian tindakan kelas ini ditunjukan untuk menjawab semua permasalahan dalam penelitian yaitu untuk mengetahui peningkatan minat belajar siswa dalam tugas-tugas biologi yang diberikan dari seorang guru kepada siswa. Dalam penelitian ini jumlah siswa yang telah menjadi objek penelitian adalah 19 siswa. Kelas VIII SMP Negeri 13 Kabupaten Raja Ampat di kampung jefman.

Di siklus ke satu ini penulis melakukan belajar mengajar terlebih dahulu. Buku yang di gunakan oleh penulis yaitu Belajar IPA Membuka Cakrawala Alam Sekitar untuk kelas VIII Sekolah Menengah Pertama/Madrasah Tsanawiyah. Saeful karim, dkk Materi yang di berikan kepada siswa BAB I tentang Pertumbuhan Dan Perkembangan pada makhluk hidup. Penulis melakukan pembelajaran selama 6 kali pertemuan setelah itu penulis memberikan tugas kepada siswa tugas yang di berikan kepada siswa yaitu tentang tahapan perkembangan manusia, tugas yang sudah ada didalam buku di halaman 8 dan belum di kembangkan oleh penulis tugas di berikan pada pertemuan ke 7 dan penulis mengamati dengan mengunakan lembar observasi, di pertemuan ke 8 penulis memberikan Angket kuensuiner kepada siswa untuk di isi dari hati nurani mereka dan tidak dipaksa dari siapapun. Peneliti member tugas, Angket Kuensuiner kepada siswa dan penulis mengamati dengan lembar observasi agar penulis bisa mengetahui ada berapa siswa yang berminat terhadap tugas-tugas biologi yang diberikina kepada mereka. Di siklus ke satu ini ada 5 siswa yang sangat berminta, 7 siawa masih ragu-ragu, dan 6 siswa tidak berminat pada pelajaran biologi. Siswa kelas VIII ketika guru member pelajaran atau tugas kepada mereka masih banyak yang bermain dari pada mendengarkan dan mengerjakan. Penulis melakukan penelitian di siklus ke satu ini selam 8 kali pertemuan.

Di siklus ke dua ini penulis masih melakukan belajar mengajar selama 2 kali pertemuan kemudian penulis memberikan tugas kepada siswa, tugas yang digunakan sama seperti siklus ke satu tapi tugas tersebut penulis sudah kembangkan kemudian penulis mengamati dengan mengunakan observasi dan di pertemuan ke 3 penulis memberikan Angket kuinsioner kepada siswa untuk di isi. Siswa mengisi angket tersebut dengan hati nurani mereka tanpa ada unsur paksaan dari siapapun. Penulis memberikan tugas, angket, dan penulisi mengamati dengan mengunakan observasi untuk mengetahui apakah sudah ada peningkatan minat siswa terhadap pelajaran biologi. Di siklus ke dua ini ada 11 siswa yang sangat berminat tehadap pelajaran biologi, 3 siswa masih ragu-ragu, dan 2 siswa belum berminat terhadap pelajaran biologi. Siklus kedua ini siswa sudah mulai giat belajar dan kurang bermain. Siswa yang sangat berminat terhadap pelajaran biologi mereka mengatakan bahwa pelajaran biologi itu sangat menarik karena mereka bisa mengetahui tentang makhluk hidup disekeliling mereka, siswa yang raguragu terhadap pelajaran biologi mereka mengatakan bawha pelajaran biologi itu gampang-gampang susah, dan siswa yang tidak suka sama pelajaran biologi mereka mengatakan pelajaran biologi itu sangat susah.

Minat atau interest senangtiasa erat hubungannya dengan perasaan individu, objek, aktivitas, dan situasi. Minat adalah kecendrungan subjek untuk merasa tertarik pada mata pelajaran atau pokok bahasan tertentu dan merasa senang mempelajari materi itu. Besar kecilnya minat akan mempengaruhi keberhasilan bagi setiap kreativitas manusia.Menurut slameto (2003: 180), minat adalah suatu rasa lebih suka dan rasa ketartarikan kepada suatu hal atau aktivitas,tanpa ada yang menyuruh. Menurut sardiman (2001 :74) minat diartikan sebagai suatu kondisi yang terjadi apabila seseorang melihat cirri-ciri atau arti sementara situasi yang di hubungkan dengan keinginan-keinginan atau kebutuhan-kebutuhan itu sendiri. Menurut singer (1991 :78) minat adalah suatu landasan yang paling meyakinkan dalam keberhasilan suatu proses belajar.seorang murid memiliki rasa ingin belajar, maka murid akan cepat dapat mengerti dan mengingatnya

6. Minat mengerjakan tugas-tugas

Siswa di SMP Negeri 13 Kabupaten Raja Ampat kampung jefman sangat senag atau berminat ketika guru memberikan pelajaran biologi jagan hanya terfokus sama satu metode pembelajaran saja tetapi harus menggunakan metode lainnya juga seperti 
metode pemberian tugas. Metode pemberian tugas ini dapat membantu siswa untuk lebihmuda belajar, siswa dapat melati dirinya untuk terbiasa belajar sendiri maupun kelompok, bertangung jawab terhadap tugas yang telah diberikan dari guru dan siswa dapat mengingat dan mengafal pelajaran yang dibrikan dari guru. Siswa sangat berminat ketika guru memberikan tugas kelompok karena dengan tugas kelompok mereka dapat belajar bersama-sama dan saling memberitahu teman yang belum paham terhadap tugs yang di berikan dari guru.

7. Faktor-faktor yang mempengaruhi minat siswa

Faktor -faktor yang mempengaruhi siswa SMP Negeri 13 Kabubaten Raja Ampat Kampung Jefman Siswa kelas VIII adalah siswa yang masih menunjukan tidak keaktifan dalam proses pembelajaran,seperti melamun, mengantuk,tidak memperhatikan pembelajaran, tidak bertanya kepada guru tentang materi yang belum jelas, tidak menjawab pertanyaan dari guru, tidak mengerjakan tugas, dan sibuk aktivitas masing-masing misalnya bicara sendiri.

\section{KESIMPULAN}

Berdasarkan hasil penelitian tindakan kelas ini dapat disimpulkan bahwa dengan mengunakan metode pemberian tugas dapat meningkatkan minat belajar siswa terhadap pelajaran biologi siswa kelas VIII SMP Negeri 13 Kabupaten Raja Ampat Kampung Jefman. Penulis simpulkan sebagai berikut :

1. Minat mengerjakan tugas-tugas biologi yang di berikan dari guru kepada siswa kelas VIII. Siswa sangatsenag dan mengerjakan tugas itu sungguhsungguh ketika menerima tugas dari guru baik itu tugas kelompok maupun tugas individu.

2. Siswa terkadang merasa bosan, mengantuk, dan ada yang rebut didalam kelas ketika guru sedang mengajar sehingga membuat siswa tidak berminat untuk belajar dan tidak ada respon terhadap materi yang diberikan dari guru.

3. Seorang guru harus mampu menarik perhatian siswa terhadap pelajaran atau materi yang di berikan sehingga siswa tidak mengantuk, merasa bosan dan ribut didalam kelas dengan mengunakan metode-metode pembelajaran salah satunya metode pemberian tugas dan guru harus bisa mengembangkan tugas tersebut sehingga siswa merasa senang dan berminat untuk mengerjakan tugas tersebut.

\section{Daftar pustaka}

Saeful Karim dkk, Belajar IPA membuka cakrawala alam sekitar ,Pusat Perbukuan Depertemen Pendidikan Nasional.

Agus, Doni Setiawan. http://sdn2ketro.blogspot.com//2011/02/metodepembelajaran-diskusi-simulasi.html diakses pada tanggal 07 April 2016.

Haisan. $\quad$ http://id.shvoong.com/socialsciences/education/2186284-pengertian-metode- pemberian-tugas/ diakses pada tanggal 07 April 2015.

N.K, Roestiyah, Didaktik Metodik, Bina Aksa, Jakarta, 1989

Aksara, Jakarta, 1989

Barnadib, Sutari Imam. 1982. Perkembangan dan Pendidikan Anak dan Ibu yang Bekerja dan Problematika Di Sekolah Menengah Pertama Di DIY, Yogyakarta: Disertasi IKIP Yogyakarta

Bloom,B.S, All Our Childdren Learning. New York Megrav Hill Book. Copyringht agnesia cheery_cizz@webmail.umm.ac.id

Depdiknas. Pembangunan Manusia Indonesia. Lembaga Penjamin Mutu, 2007

Departemen Pendidikan dan Kebudayaan, Direktorat Jendral Pendidikan.

Jakarta, 2011

Hamalik, Oemar. (2005). Proses Belajar Mengajar. Jakarta: Bumi Aksara.

Hartono. 2008. SPSS 16.0 Analisis Data Statistik dan Penelitian. Yogyakarta: Pustaka Pelajar.

http://makalahdankti.blogspot.com/2012/08/mengenal -kelebihan-dan-kekurangan.html diakses pada tanggal 07 April 2016.

Atminah, Nanik. Proposal, Pemanfaatan Labotarium untuk meningkatkan minat belajar siswa pada materi struktur dan fungsi jaringan tumbuhan, STKIP Muhammadiyah Sorong, Sorong, 2013.

Ula, Maman, Laporan pelaksanaan kegiatan magang pada asisten tata praja bagian adm. Pemerintahan Sekretaris Daerah Kab. Sorong, Universitas Cenderawasih, Jayapura, 2010

Drs. Syaiful Bahri Djamarah, M.Ag, Psikologi Belajar, Edisi II, Rineka Cipta,

Listiani, Arifa Tika, Skripsi Hubungan antara metode pemberian tugas dan prestasi belajar siswa pada mata pelajaran bahsa Arab, Universitas Islam Negeri Sunan Kalijaga, Yogyakarta, 2014

Munsyi, Abdul Kadir, Pedoman MengajarBimbinganPraktis Untuk Calon Guru, Usaha Nasional, Surabaya, Tanpa Tahun

Psikologi Pendidikan, Materi Dasar dan Teori Pendidikan Akta Mengajar V, 1981

Sumitro. Dkk, Pengantar Ilmu Penedidikan, FIP UNY, Yokyakarta, 2003. Diakses pada 04-032016

Suryabrata, Sumardi. 1987. Psikologi Pendidikan. Jakarta: CV. Rajawali.

Walgito, Bimo. 1983. Psikologi Sosial Sebagai Pengantar. Yogyakarta: Psikologi UGM Yogyakarta.

Wingkel, W.S. (1985). Psikologi Pendidikan dan Evaluasi Belajar. Jakarta: Gramedia.

Zuhairini, H, Metode Khusus Pendidikan Agama, Cet I, Usaha Nasional, Surabaya, 1977 